\title{
The Urban and Environmental Impact of Madrid's Ciudad Universitaria: A Comparison Between the First Campus and the Post-War Campus
}

\author{
José Luis González Casas*, Jara Muñoz Hernández \\ Departamento de Ideación Gráfica Arquitectónica, Universidad Politécnica de Madrid, Madrid 28040, Spain
}

Corresponding Author Email: jlgonzalezcasas@gmail.com

https://doi.org/10.18280/ijsdp.150612

Received: 16 January 2020

Accepted: 5 July 2020

\section{Keywords:}

20th century, 3D topography modelling, drawing, heritage, landscape, Spain, university

\begin{abstract}
Ciudad Universitaria is the Madrid campus that was planned between the 20s and 30s of the last century. For its location a natural environment on the border of the city was chosen, where agricultural crops and lush gardens predominated. It was very little built and often frequented by locals. The construction of the campus in this place aroused one of the first reactions of an ecological nature in the Spanish press of the time, where the modification of the landscape to install the new faculties was strongly criticized. Although the design of the first campus was not as respectful as it could have been, in this research it is intended to prove, using drawings and 3-dimensional topographic modelling, how the real problem came after the Spanish Civil War. At that time, the reconstruction of the University gave way to an uncontrolled growth of the buildings, an aggressive modification of the topography and a strong environmental impact caused by roads and traffic intensity, which have become the essential conflicts facing the current campus.
\end{abstract}

\section{INTRODUCTION}

In the first decades of the Spanish 20th century, Madrid's Ciudad Universitaria was probably one of the largest economic, cultural and social investments of the country, and also one that awoke many hopes. The creation of a university campus in Madrid was essentially motivated by the combination of four factors: the logistic factor - due to the lack of space and poor condition of the pre-existing faculties, and in particular that of Medicine - and the sanitary, urban and political factors.

At that time Madrid had only one university, the Central University, which offered all the higher studies that were taught then: Philosophy and Letters, Science, Medicine, Law and Pharmacy. It was also the only university in Spain that granted the title of doctor. But, despite its academic and institutional importance, the University of Madrid did not have its own campus and the different careers were taught in buildings distributed throughout the city, generally old and poorly preserved and scarcely equipped with the necessary material for proper teaching. This situation resulted in the claim, not only by students and professors, but also citizens and politicians, of a new space that would house the university [1].

Obviously, such a major urban operation would have an immense impact on the place where it was located, which was finally the estate of La Moncloa, formerly a Royal Estate and a territory very close to Madrid. There, some buildings already existed and, above all, crops in charge of the School of Agricultural Engineers and gardens open to the public.

\section{THE GRAPHIC MEANS FOR THE RESEARCH}

In order to carry out this research, we have followed a methodology used regularly in our scientific works based on the use of the drawing of architecture, which help us to analyse and organize our study subject.

We can understand drawing from different approaches. For a start, it is an essential background source for the work we carry out. Secondly, it is also a scientific tool to travel to the past, in what we understand as a process of graphic reconstitution [2], and finally, it is the means with which to illustrate our results.

In this particular case, the process has been as follows. First of all, from a planimetry of the year 1927 georeferenced with the base of the current cadastral map, we have superimposed the buildings and roads of the 1928 campus project. From this drawing, we have reconstituted the image of this territory in 1936, understanding which earthworks had to be carried out in order to build the faculties and roads. In a gray line we have kept the silhouette of the planned buildings that were not built. On the other hand, based on the current map of Ciudad Universitaria, we have "gone back" in time until 1970, when the new reconstruction was almost completed, and the most aggressive landscape actions had been accomplished.

In addition, both terrains have been modeled in three dimensions, appreciating much more the work of clearing and embankment that this landscape experienced.

Finally, we compare two plans built scientifically and with the same geographical reference, to extract the results and conclusions that are developed below. This analysis also aims to be a first step to take up the debate about the future of the campus development and how can we solve the main current challenges in order to recover the initial idea of the campus. 


\section{THE FIRST CAMPUS IN A NATURAL ENVIRONMENT (1927-1936)}

The need for a new headquarters for the Central University of Madrid led to the development of a new Ciudad Universitaria project that would combine faculties, laboratories, residences and sports fields in the same space. The project was, in general, well received and only a few voices - from the conservative and Catholic sectors complained about the danger that might involve concentrating large student masses [3].

One of the most controversial points in the debate about the new university complex focused on its location. The chosen estate, La Florida and La Moncloa, had become in practice almost a natural park very frequented by Madrid's citizens, especially those of the most modest classes, for being a very accessible place thanks to the tram that reached Puerta de Hierro. Florida as a whole should not have been a very leafy territory, but rather an agricultural landscape with scattered vegetation. But a part of the estate, the Manzanares valley, was uniquely lush. In addition, the gardens around the Moncloa Palace, which had once again been open to the public in the mid-twenties, after being restored by Javier Winthuysen, were a particularly well-cared and quiet place. All this made this territory a place of frequent parties, picnics and walks (Figure $1)$.

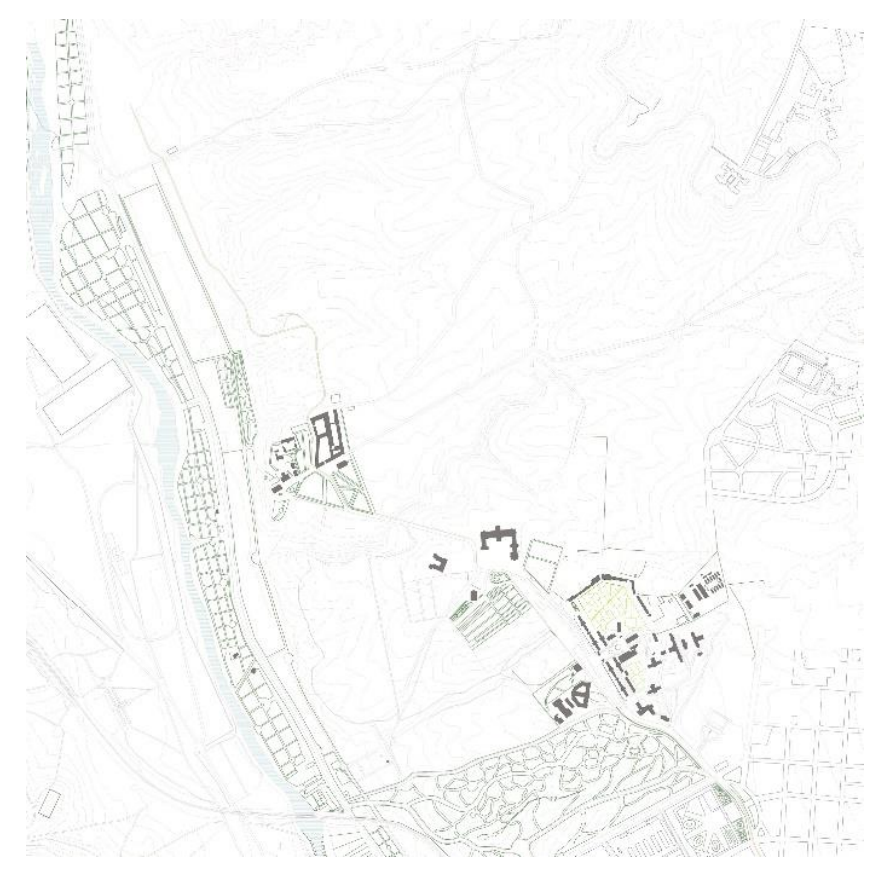

Figure 1. State of La Moncloa in 1927. Drawing of the authors

Supporters of the location in La Moncloa were in the circles near the king. That is why the small available extension of only 35 hectares was not considered, nor the successive purchases that, consequently, should be made to expand it, since it was expected that the pressures of the king would secure the transfer of the property to the Ministry of Public Instruction [4]. It was neither appreciated that with this operation Madrid lost one of its most popular public parks, a situation that led to a large number of detractors of the project.

The controversy that generated the news about the location of the new campus was capital and extended throughout the twenties and thirties. The Madrid press, except the monarchist and conservative, did not hesitate to claim the need to protect the natural park of La Moncloa. As Pérez-Villanueva points out [3], "it was an innovative, modern form of protest, of proportions and for purposes unknown before in Spain, aimed at defending a natural area". In addition, it was the press that served as spokesperson for complaints through countless articles that all citizens could read.

Some chronicles insisted on the landscape value of the area, others on its benefits for the health of Madrid people. Winthuysen himself [5] summed up the critical opinion in his article "The felling of Ciudad Universitaria's pine forest". There were numerous writings calling for resistance, some in a truly heated tone. Many of them were anonymous, others included authors, almost always of Republican affiliation [3]. The eloquence of many of the titles reveals the intensity of criticism. The Republican president Manuel Azaña also lamented in his memoirs that the construction of the campus which he saw with pleasure - was carried out at the cost of the destruction of La Moncloa.

The election of La Moncloa had, however, its defenders. As advantages, the proximity to Madrid and the existence of some charity-assistance institutions, which would be completed with the hospital and the Faculty of Medicine. Moreover, the extension of La Moncloa and its natural landscape were ideal to carry out the concept of a university inspired by American university campuses, surrounded by nature without being too far from the city center [6].

Actually, the use of La Moncloa simultaneously as a campus and as a park was possible. In fact, in the different versions of the Ciudad Universitaria project it is clear that the space was only partially occupied. In addition, the campus extended over the upper plateau, which was the most arid zone, so that the gardens and nurseries were kept available to the public. All these more or less heated articles of opposition to the new campus must be contextualized in the medium from which they come. It is true that the Ciudad Universitaria project was not as respectful of its surroundings as it could have been, but it is no less true that Florida was not the leafy and fresh garden of which some of these writings spoke. There was no lack, thus, of exaggeration in complaints, but the way - quite aggressive - in which the Ciudad Universitaria was planned did not help soften the conflict.

Finally, on May 17, 1927, the Construction Board of the Ciudad Universitaria was established, an organism in which architects and political and academic authorities were present. Once the location of the Ciudad Universitaria in La Moncloa was decided and given the varied landscape of institutions that already existed in the place, the campus planners were in the position to decide which elements they would conserve and incorporate into the project and which not.

The main need was to increase the lands of the future campus. This extension necessarily affected the School of Agronomists, which had occupied most of the land in La Florida for more than half a century, with its buildings and its fields of practice. It was tried to dispose for the campus of all the lands that were east of the Paseo de La Moncloa. After several avatars (purchase of adjoining land, transfer of some institutions), in 1928 the plot of approximately 320 hectares was completed.

At that time, the demands of professors and academics of different specialties had led to discard a campus dedicated only to Medicine, to move on to develop more ambitious approaches to a complete campus that would bring together the different disciplines of knowledge, combining in its design 
"the English scheme of 'colleges + sports', the German combination of seminars and laboratories, the traditional Spanish administrative unit, and the North American 'campus', with its selective and elitist load" [4].

This search for modernity led the Construction Board to make several trips to Europe and the United States [7]. The latter, carried out in the autumn of 1927, in which the Harvard, Yale, Princeton, Columbia or MIT campuses were visited, among others, changed the first ideas of the Construction Board, which understood that they should go beyond the idea of a medical complex to create an integrated set with all the teachings and activities that students and professors could demand in their daily lives [8].

\subsection{The project of Ciudad Universitaria}

At the end of 1928 there was already a first project of the complex. The basic scheme of the proposal adopted can be described very synthetically based on two of the initial drawings that are preserved (Figures 2 and 3).

The first of these is a scheme of traffic lanes of Madrid in whose upper left margin there is a shaded area, corresponding to Ciudad Universitaria, integrated into the new axis of the city's northern exit, which would be the new La Coruña road. However, this road infrastructure, understandable in its time, has subsequently translated into one of the fundamental problems that the campus has suffered since the last quarter of the 20th century, due to the increasing intensity of road traffic and its disturbing effects of segregation.

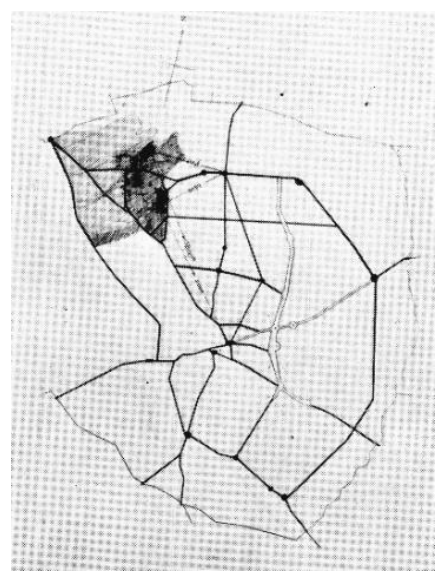

Figure 2. Scheme of traffic lanes in the city of Madrid (AGUCM)

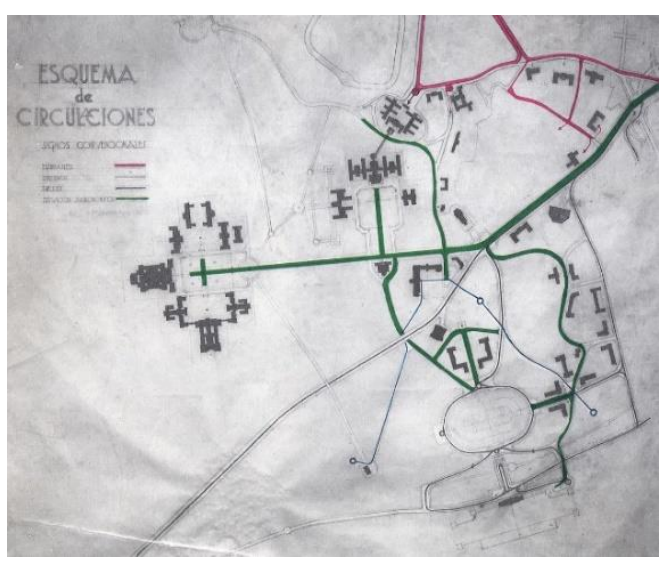

Figure 3. Proposal for the Ciudad Universitaria layout, 1929 (AGUCM)
The second drawing is the initial plan of the proposal, whose basic structure is established by inserting in the new north exit of the city a "branch" that constitutes the main axis of the project, the today called Complutense Avenue - then University Avenue-. At the end of it is the Paraninfo or Rector's Office - for which several projects were made, but never built - flanked to the east and west by the groups dedicated, respectively, to the Sciences - Mathematical, Physical and Chemical - and the Humanities -with the Faculty of Philosophy and Letters, the Faculty of Law and the Great Library of Letters-, while the medical campus is organized around the middle of this axis around a large square, open to the main road. After the trip to the United States and the analysis of the campuses that were visited there, they tried to apply the North American model as faithfully as possible: the axial distribution of the buildings and the presence of nature in their surroundings became fundamental premises. The Ciudad Universitaria would also have sports fields, museums, libraries and a music conservatory with an auditorium.

Faced with the emphatic composition that would be adopted in the postwar period, the union of the new complex - formed by the campus and the pre-existing buildings - with the city was established through a slightly winding path, which retained the picturesque character the area already had, with an asymmetric section formed by a tree-lined sidewalk on its eastern margin and tram tracks on the western side, trying to adapt to the irregular topography and existing buildings. The only sign that betrayed the presence of the new university near La Moncloa square was the cruciform floor plan pavilion that housed the seat of the Government Board.

As the Ciudad Universitaria project evolved, it was also proposed to dedicate a part of the campus to the Fine Arts. The faculties of this area would be located on the other side of the new La Coruña road, in the western part of the estate. In this way, the School of Agronomical Engineers, who lost many of its fields of practice with these operations, was left as a hinge between the sanitary and artistic campus, at the bifurcation point of the two main roads of the complex.

\subsection{The impact of the works in La Moncloa}

The works began at the end of the reign of Alfonso XIII and were developed during the Second Republic. The irregular topography of the Moncloa, which had tried to be respected until then by the layout of roads and the tram, was profoundly altered by complex and expensive clearing and embankment works, whose magnitude records numerous photographs and even small filmings of the moment. The objective was to form single-level platforms on which the faculties and other complementary buildings began to settle. There was a mistaken and somewhat absurd conception of the buildings, which needed a flat support, instead of adapting to the existing terrain, and the impact and cost of the necessary landings were not assessed [4]. The immediate results turned out in the devastation of the scarce existing vegetation and the appearance of embankments, clearings and steep artificial slopes. This forced the layout of alternative roads and the construction of large containment infrastructures, special foundations, viaducts and bridges. In fact, beyond the presence of the buildings themselves, the greatest impact on La Moncloa caused by the Ciudad Universitaria came with the civil infrastructures and the aggressive earthworks.

Despite so many alterations, most of the existing buildings and part of the road network were also respected. In this sense, the central situation within the estate of the School of 
Agronomists forced to a certain extent the urban structure of the project. The main axis of the Ciudad Universitaria, topped by the Paraninfo, part of the end of the Moncloa walk in its encounter with the School [9]. The existence of the Agronomists building and the road, which also had a whole tram infrastructure, marked the most appropriate point for the start of the main axis of the campus, which was placed in this way between the School and the Asylum of Santa Cristina. If we look at the plan of 1936, it is easy to see that, with the structure that was intended to give to the project, it would have been difficult to arrange the origin of the University Avenue at another point.

On the other hand, the drawing of the 1929 traffic lanes shows an outline of the structure of the future campus, in which the central axis starts approximately at the point we have seen, to follow a clear north-south direction. However, Complutense Avenue is not perfectly facing north, but slightly inclined towards the northwest and almost in parallel with the School of Agronomists. By extension, the rest of the campus, which is organized along the axis marked by the road, also establishes the same relationship with the Agronomists building. Although we do not preserve all the design process of the Ciudad Universitaria, it seems likely that this mild turn of the main axis with regard to the first intentions sought to integrate with the buildings of the School, which were thus incorporated into the orthogonal grid proposed by the project of the campus, even if formally they were architectures outside the project.

The arrival of the Ciudad Universitaria greatly affected the School of Agronomists, since it occupied much of the land of La Florida (Figure 4). With the construction of the new university, the School lost a very important surface of its fields of practice $[10,11]$. What came to be built before the war meant the loss of orchards, when the School of Architecture was erected; the irrigation field, which was dismantled after a large part of its land was occupied by the medical group and the University Avenue; a sector of the olive grove next to the Botanical Agricultural Garden, which disappeared when filling the Degollado stream to build the sports fields; and some lands of work of the Farm that were in the zone occupied by the Faculty of Philosophy and Letters.

The impact that the Ciudad Universitaria produced on the School of Agriculture was reflected in the fields of practice and work, of which much surface was lost, but not in the buildings, which were respected by the project. However, the great civil works that were coordinated in time with the construction of the campus did have consequences on some buildings, which had to be demolished and relocated to other parts of the estate.

Around 1930 the new north exit of Madrid began to be built. This was to be a first-order route and, hence, of a width much greater than the old road - which ran parallel to the Manzanares River - and, of course, than those that crossed La Florida, which in most cases were merely tree-lined paths.

Although, to a certain extent, the route of the old road of $\mathrm{La}$ Moncloa was maintained, especially in the section in front of the Asylum of Santa Cristina, when arriving at the School of Agronomists it turned and continued in a long straight line crossing the dell of the Cantarranas stream and leaving the Model Farm on the left. In this way, it did not affect the main buildings of the Farm and passed through areas of lesser slope (Figure 4). Even so, there were several buildings that were demolished with this operation, such as the Machine Testing Station.

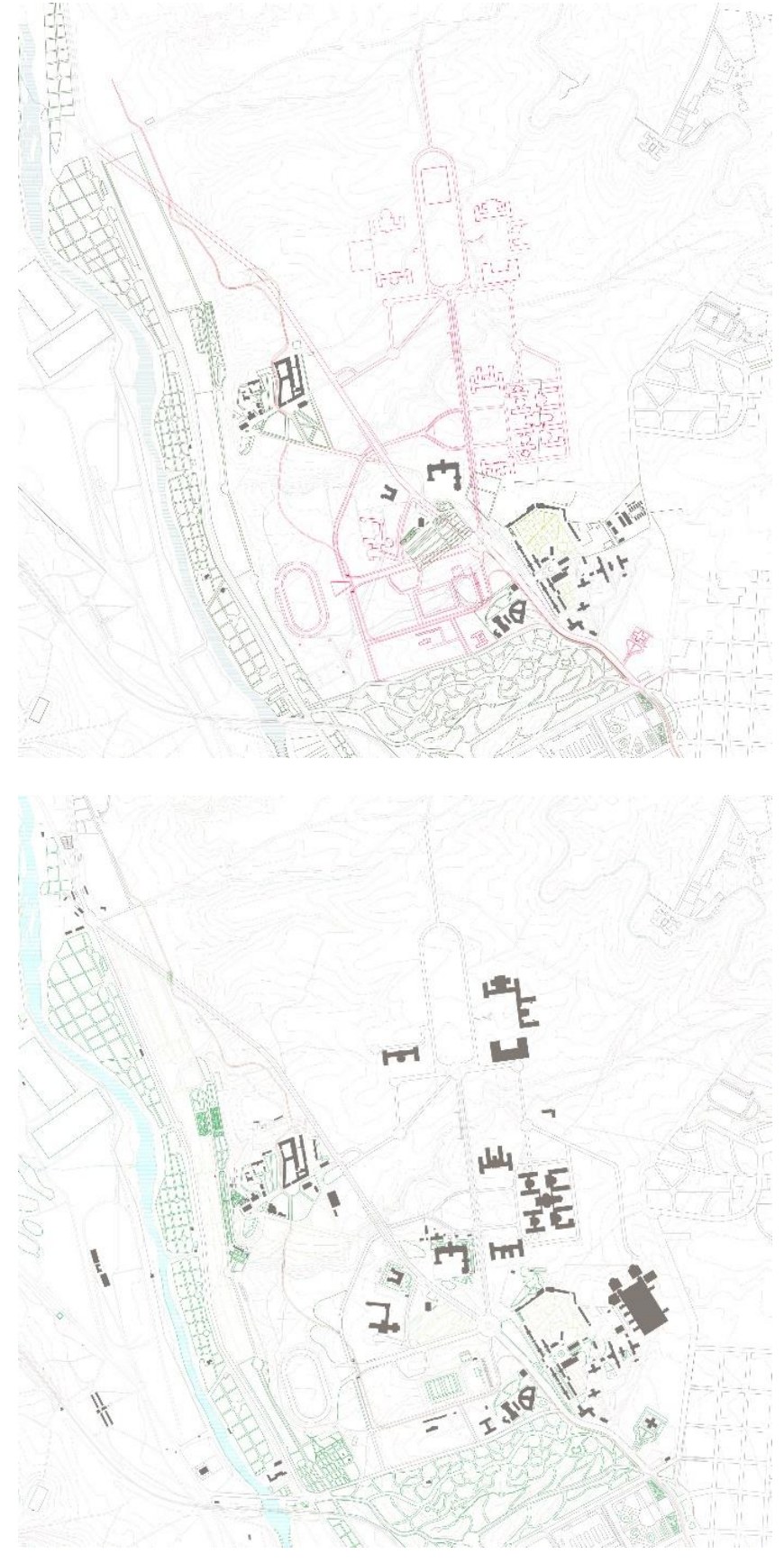

Figure 4. Above: State of La Moncloa in 1927 with the overlapped project of CU. Below: State of the Ciudad Universitaria in 1936. Drawings of the authors

The construction of the road and the campus also forced the modification of the tram. An attempt had been made to keep the existing line in operation during the first part of the works of the Ciudad Universitaria [4], but the problems that it caused forced its redesign. Until then, La Moncloa promenade had combined the tram traffic with road traffic, organized in bands separated by tree-lined alignments. The new road, already designed for much faster traffic, did not incorporate the tram. Thus, the tram entrance to La Florida from the La Moncloa square followed a parallel path to the old one along the sidewalk, although with a double track, which was maintained throughout its route.

The design of these two new infrastructures required finding a solution to save the deep dell of the Cantarranas, without creating slopes on the road or on the tram line - which was the option that had been adopted so far. In response to this 
problem, two great engineering works headed by Eduardo Torroja were built in La Moncloa: The Quince Ojos viaduct, over which the La Coruña road passed, and the Air viaduct, built for tram circulation.

\section{THE WAR IN MADRID'S CIUDAD UNIVERSITARIA}

In July 1936 the Civil War broke out in Spain after the military coup d'etat initiated in North Africa. The rebel troops would finally reach Madrid in November 1936 and on 15th November they would cross the Manzanares River, beginning the fighting on the grounds of the Ciudad Universitaria, which would last until the end of the war.

The rebel troops occupied most of the campus, reaching the Clínico Hospital in the east, the Faculty of Philosophy in the north and the Parque del Oeste in the south. During the next 29 months of fighting on the university grounds, all kinds of war material and tactics would be used, which would radically transform the existing landscape. The war was transformed into a trench war, in which the only shelters that were safe from the direct impacts of the different weapons were the dells created by the streams that crossed the Ciudad Universitaria. The war of mines and countermines was increasing over the months, causing some of the most important damage as well as craters in the landscape that are still recognizable today [12].

After three years under the fire of arms, at the end of the war numerous buildings and infrastructure were damaged or even destroyed [13]. What had been a natural park was now a totally desolate area, in which the vegetation of some green areas, such as the bordering Parque del Oeste, had completely disappeared.

\section{POSTWAR AND RECONSTRUCTION}

After the war, Ciudad Universitaria had become a completely desolate place on which it was necessary to take a decision. Franco's regime initially maintained the ruin as a witness to the victory, and even valued the option of keeping it as a reminder of what happened, following the example of Belchite. Finally, the idea of the university project reconstruction was imposed, due to the high costs of maintaining the ruin and the numerous possibilities offered to the regime by this university campus.

Two models are preserved as witnesses to these two ideas of ruin and reconstruction. The first one, a model that shows the state in which the Ciudad Universitaria was left at the end of the contest, presents a thorough execution that allows even a smaller-scale memory of the ruins. The other large model, which was built in 1943, is an example of the symbolic value that Franco would give to the reconstruction of the Ciudad Universitaria. This second model shows an ideal approximation to what was intended to be done on campus, but which ultimately did not coincide with what was built.

\subsection{Ways of carrying out the reconstruction}

Once the decision to rebuild the campus had been adopted, the reconstruction works began, returning to the initial pre-war project. In February 1940, a Law creating a new Construction Board for the Ciudad Universitaria was published, which would be chaired by Franco, together with authorities of the
Ministries, the rector of the University of Madrid, the deans, the mayor of Madrid and Modesto López Otero. The latter had already been part of the Construction Board during the reign of Alfonso XIII and the Second Republic, which is another example of the intention to continue with the project. However, it should be pointed out that some changes will be made with the idea of resignifying the space and thus accommodate the symbols of the Franco regime [14]. These criteria prevailed over the landscaping and urban values of the initial project and they are the origin of the disorderly and massive development of the following decades.

The idea of reconstructing the Ciudad Universitaria offered many possibilities to reinforce the image of the regime given the characteristics of this space. The axial layout of the complex allowed to show the power of the rector, as well as having a representation of the Church and the Phalange, the two great ideological pillars of the regime. For that purpose, it was first thought of a large Paraninfo and Rectorate, based on the first sketches made in 1928, to which fascist symbols would be added to resignify the space. This idea remained in the paper, though. At the entrance to the campus from Moncloa the José Antonio Student's Hall was built, an example of Phalange architecture. Chapels were also installed in all faculties and the church of Santo Tomás de Aquino was built which would afterwards become the current Museum of America. These three buildings would be joined by another element as a reminder of the battle and the Francoist triumph: The Victory Arch.

Besides these interventions that we could describe as an ideological reconstruction, a solution had to be found, regarding the rest of the buildings, more or less dilapidated, that remained on campus. On the one hand, there would be those buildings that were not raised again, and whose footprint has been lost, totally or partially. On the other hand, within the group of buildings that were rebuilt we can establish several categories: new buildings, an operation called by some authors as neoreconstruction; literal reconstruction of buildings; and the renewal of the external image or change of skin, as in the case of the School of Architecture or the School of Agricultural Engineers. Muñoz and González develop this subject and propose a classification within this groups of all campus buildings [13].

Following these criteria, the works advanced throughout the 1940 s, continued by the inauguration or reopening of numerous faculties. On October 12, 1943, the most important inauguration took place, both quantitatively and also symbolically.

\subsection{The exponential development of the campus}

By the 1950s, most of the buildings existing before the war had already been rebuilt. That other buildings whose construction had not started during the Republic, but integrate the project, were progressing well, such as the Law Faculty. Thus, the initial project was finally completed, with some stylistic variations. The completion of the different buildings coincides with the beginning of the process of economic recovery in Spain, which will cause in the following decades a great growth of the city of Madrid in terms of economy, industry and urbanism, giving also place to a greater demand for university studies.

At this point, when the Ciudad Universitaria had practically exhausted the building surface intended in the project, two options could be expected to continue its growth: on one side, 
the development of an expansion plan of the existing campus, adapting it to new needs. On the other, the creation of new campuses in the city that absorbed this demand. Faced with these two options, the Ciudad Universitaria would continue to grow disorderly, gradually filling up without following specific directives.
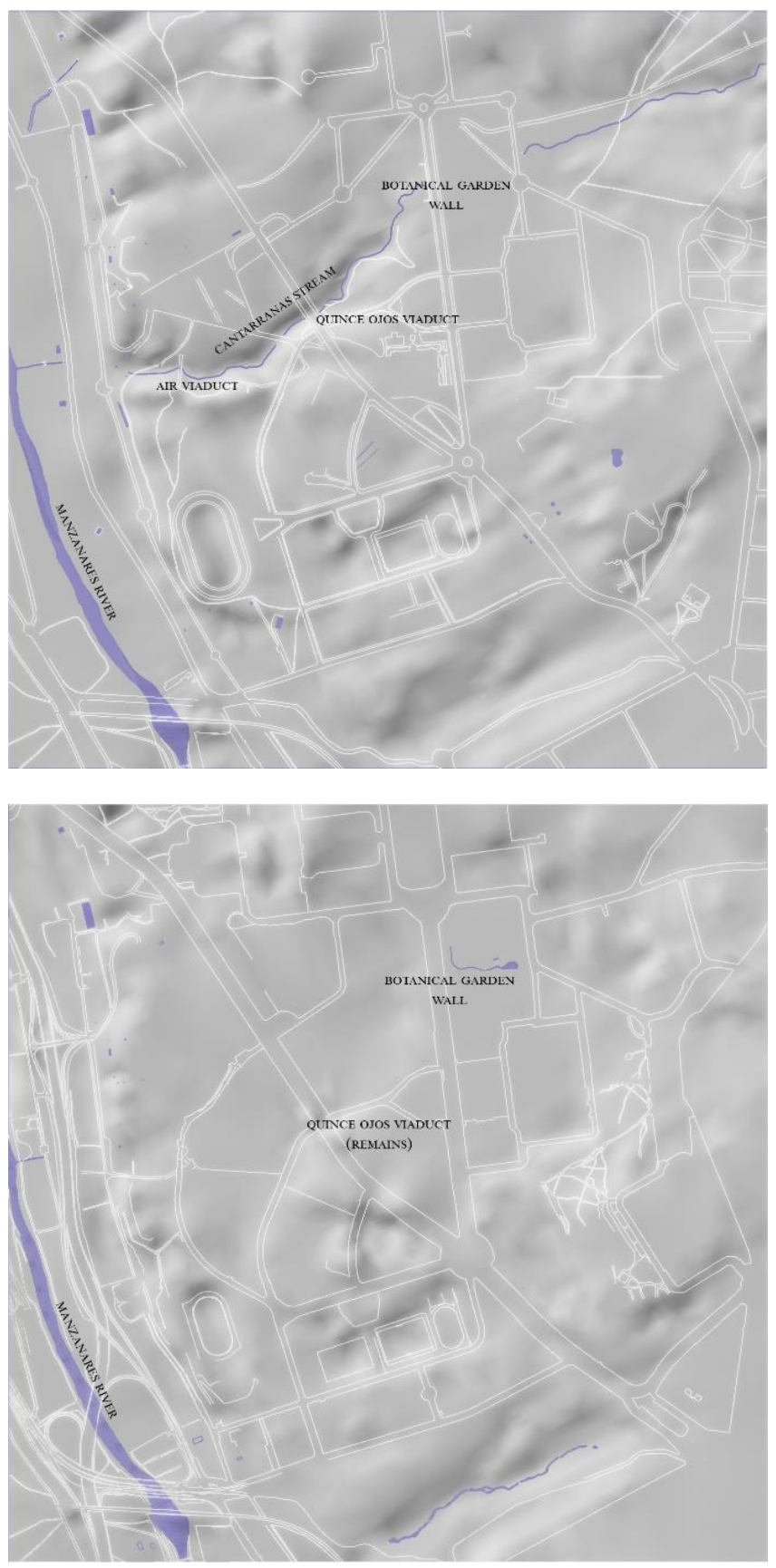

Figure 5. 3D models of the topography in 1936 (above) and 2015 (below). Drawings of the authors

There was a progressive increase in the number of uses within the campus, with the construction of new buildings and the expansion of many of the existing faculties. From the landscape point of view, the most important actions were the ones related to the changes made in the irregular orography of the Ciudad Universitaria (Figure 5), with the filling of the Cantarranas stream dell, which caused the Air viaduct to be completely buried and other infrastructures such as the retaining wall of the Botanical garden or the Quince Ojos viaduct were partially covered. The rugged and natural land of La Moncloa gradually disappeared.

If we visit the whole of the Ciudad Universitaria, we can see the arrival of new inhabitants, such as new faculties, student dorms and other institutions. In general terms, we observe that while the land area occupied by buildings in 1936 was about $130,000 \mathrm{~m}^{2}$, in 1970 this occupation had increased more than a $150 \%$, without accounting for the land allocated to sports fields.

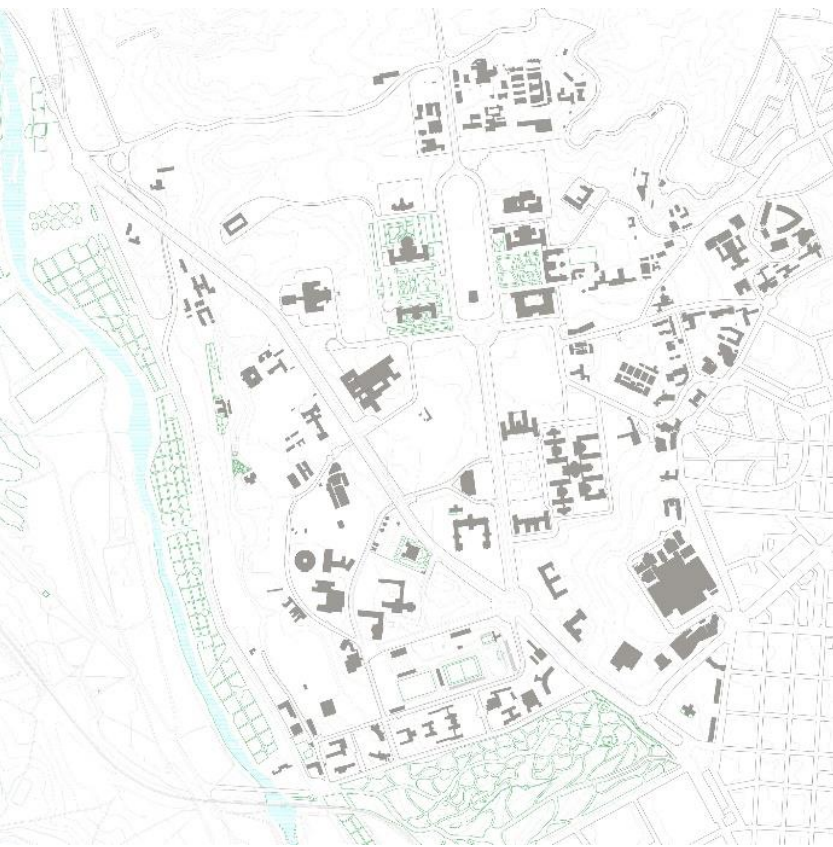

Figure 6. State of the Ciudad Universitaria in 1970. Drawing of the authors

Hence, around 1970 the Ciudad Universitaria had undergone an important process of clogging (Figure 6), which only increased until the 1990s and, in a more controlled way, until today. Thus, the area devoted to buildings, roads and parking areas at the expenses of the green areas that characterized the initial campus project and its American influence has grown considerably.

\subsection{Analysis of the conditioning factors of the Ciudad Universitaria}

As the successive plans of the Ciudad Universitaria (project-1936-1970-2019) show, there is a clear decrease in green spaces while the number of buildings and traffic increase. La Coruña road, which crosses the campus, has caused a gap within the complex. This element, which was already present from the beginning of the process, has been expanding over the years, mainly due to the rise of road traffic. The small road for the few vehicles in the 1920s is today one of the main highways of the capital. This has led to the creation of not only a physical barrier, but also one of air and acoustic pollution, which distorts the original idea of a project in which buildings would be surrounded by nature, as a perfect environment where the academic work would be developed. Therefore, three essential factors can be determined in the degradation of a project that intended to join education and nature, and also in the destruction of the idyllic environment in which it was built: the lack of a global project for the Ciudad Universitaria, 
the appearance of numerous constructions and the important increase of traffic in the area

During the first years and in the post-war period, the tram was the main mean of transport and most of the students arrived to the campus by tram, bus or on foot. Later, the use of the private car has increased, while the tram disappeared. It was replaced by the subway, which has become the main transport system of the Ciudad Universitaria, but despite this, the use of private transport is higher, with the consequent flourish of the parking area in recent years.

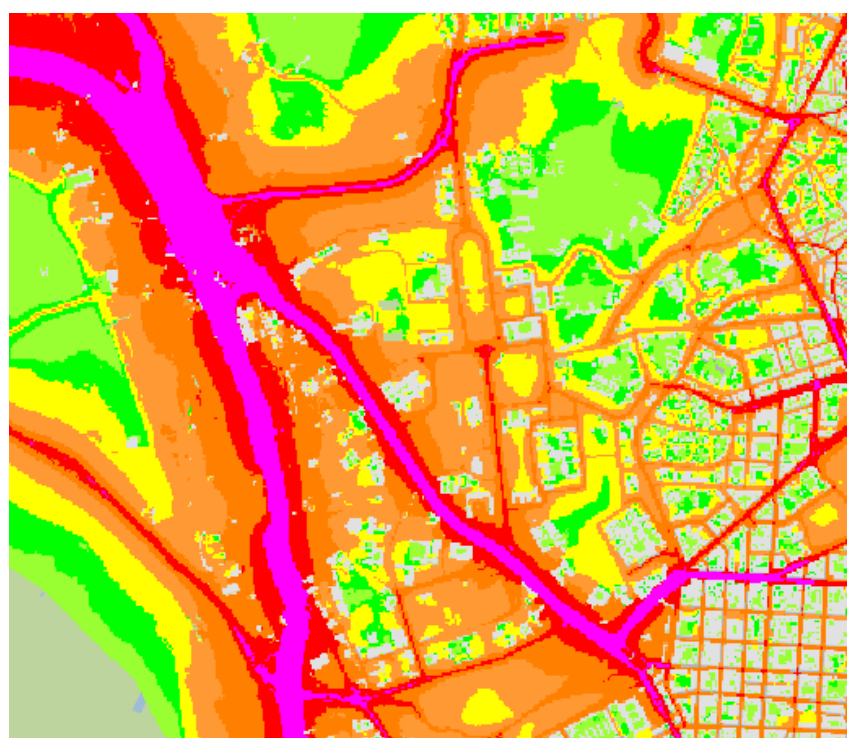

Figure 7. Strategic noise map of Madrid (Madrid City Council)

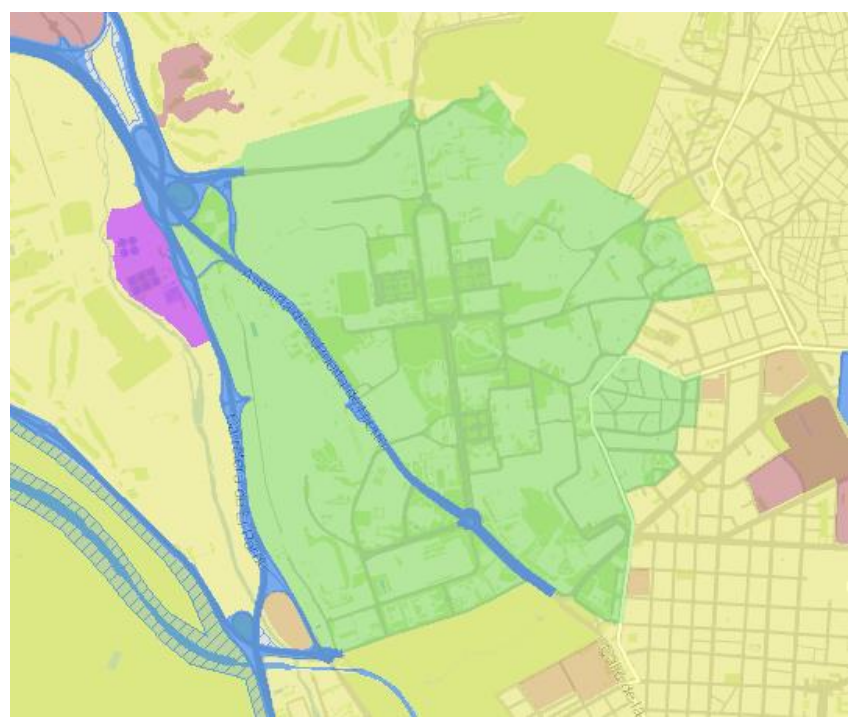

Figure 8. Acoustic areas map, 2018 (Madrid City Council)

This increased traffic over time, especially since the 1960s, coincides with the growth of neighborhoods and towns in the northwest, which go in and out of Madrid through this area, turning the campus into a vehicle crossing point. The strategic noise map prepared by the Madrid City Council helps us to directly visualize the importance of traffic on the site, taking the traffic density as directly proportional to the level of acoustic pollution. In the plan, the lowest noise level is shown in green and the highest in pink. This map shows a fundamental strip that crosses the campus from northwest to southeast which corresponds to La Coruña road and also highlights the noise zone created by the bypass that generates the western limit of our area. In addition to these two main noise strips, we see other secondary ones in red that penetrate the Ciudad Universitaria from the east or that cross it from north to south like Complutense Avenue, the main axis of the campus. By contrast, the plan of acoustic areas of the same area drawn by the City Council proposes a large area dedicated to educational and sanitary use crossed by a narrow traffic area being in clear contradiction with the reality shown by the acoustic map (Figures 7 and 8). Noise and environmental pollution are directly linked, since in this area the main source of polluting gas emissions are vehicles, due to the lack of industry or other polluting sources in this area. Therefore, the noise map also reflects the air pollution generated by traffic. Regarding water pollution, it is not particularly remarkable, although it is true that the river system of the area has been altered because of the disappearance of the Cantarranas stream during the post-war reconstruction.

Thus, the increase in the presence of the car in this space is not due to its use. The presence of La Coruña road since the beginning of the project is one of the factors that conditioned its planning and that has conditioned its use, as the large amount of traffic generates a large physical barrier for the pedestrian, as well as an acoustic and environmental pollution scar.

A solution for this issue has not been found yet. Many experts, like Pablo Campos [7] are in favour of burying the road. Other authors, on the other hand, believe that the magnitude of this action makes it more reasonable to think about a redistribution of traffic. This is the case of Luis Moya [15], who advocates diverting vehicles through the nearby M30 bypass, to moderate traffic inside the university campus.

\section{CONCLUSIONS}

After the analysis of the drawings that have been explained previously, the main conclusion we can draw is that the development of the Ciudad Universitaria had a considerable impact on the environment, first with the construction in the 1920 s and later during the reconstruction after the war. However, the original project was more sensitive than has been thought, and knew how to place itself in the emptiest and less interesting areas from the landscape and agricultural point of view. Therefore, the highest destruction of La Moncloa would arrive in the 1960s, with the filling of the stream troughs to contribute to the uncontrolled construction in the free spaces of the campus and with the growth of the rolling roads that cross the Ciudad Universitaria, generating, not only an alteration of the landscape, but an important problem of noise and accessibility between the various faculties. We can therefore say that the impact of the postwar campus was much greater.

It is clear that, despite the decrease in wooded surface, the Ciudad Universitaria is still a much less dense area than the adjoining neighborhoods, where the gardens are very small. Therefore, it would not be advisable to continue building on campus, as it will definitely contribute to blur the dreamt project. According to this it would be necessary to continue researching on ways to reorder traffic, which would enable recovering pedestrian space, while reducing pollution.

In conclusion, it would be much more interesting to consider reordering the Ciudad Universitaria than extending 
the built surface, in order to recover the spirit of modernity that was sought in the early twentieth century using the present and future planning and technology.

\section{ACKNOWLEDGMENT}

Jara Muñoz Hernández has a pre-PhD contract (FPU) financed by the Spanish Ministry of Education, Culture and Sports. (FPU15/01782)

\section{REFERENCES}

[1] Rodríguez-López, C., González Casas, J.L., Mauleón Pérez, L., Muñoz Hernández, J. (2016). From fields of Mars to palaces of Minerva: The reconstruction of Madrid's Ciudad Universitaria. In Momoitio I., Núñez Monasterio, A. (eds.) Falling and raising. Heritage reconstruction after a war. Fundación Museo de la Paz de Gernika, Gernika. (in Spanish).

[2] Ortega Vidal, J., Martínez Díaz, Á., Muñoz de Pablo, M.J. (2011). Drawing and building life. EGA. Journal of Architectural Graphic Expression, 18: 50-63 (in Spanish). http://dx.doi.org/10.4995/ega.2011.1335

[3] Pérez-Villanueva Tovar, I. (2018). Madrid's Ciudad Universitaria (1927-1931). In Rodríguez-López, C., Muñoz Hernández, J. (eds.) Towards the centenary. 90 years of Madrid's Ciudad Universitaria. Ediciones Complutense: Madrid. (in Spanish).

[4] Chías Navarro, P. (2019). The Ciudad Universitaria in Madrid and the politic ideologies: A 90 years old built heritage. Sophia Austral, 23 (in Spanish). http://dx.doi.org/10.4067/S0719-56052019000100177

[5] Winthuysen, J. (1931). The felling of Ciudad Universitaria's pine forest. Crisol: 5. (in Spanish).

[6] Marañón, G. (1924). About the Ciudad Universitaria. El Debate: 1. (in Spanish).

[7] Campos Calvo-Sotelo, P. (2002). The journey of utopia. Editorial Complutense: Madrid. (in Spanish).

[8] Rodríguez López, C. (2015). Landscapes of a War: Madrid's Ciudad Universitaria. Universidad
Complutense de Madrid: Madrid. (in Spanish).

[9] González Casas, J.L., Muñoz Hernández, J. (2018). Drawing for heritage dissemination. The birth of Madrid's Ciudad Universitaria. International Journal of Heritage Architecture, 2(2): 359-371. http://dx.doi.org/10.2495/HA-V2-N2-359-371

[10] Losada Villasante, A., Rodríguez Sinobas, L., Sánchez Calvo, R., Juana Sirgado, L. (2006). A small story around the Hydraulics and Irrigation Area at the School of Agricultural Engineers of Madrid. Biblio 3W, Revista Bibliográfica de Geografía y Ciencias Sociales, 11(678): 1-36. (in Spanish). https://doi.org/10.1344/b3w.11.2006.25671

[11] Muñoz Hernández, J. (2018). The School of Agricultural Engineering in La Florida-Moncloa. In Rodríguez-López, C., Muñoz Hernández, J. (eds.) Towards the centenary. 90 years of Madrid's Ciudad Universitaria. Ediciones Complutense: Madrid. (in Spanish).

[12] Calvo González-Regueral, F. (2012). The Civil War in the Ciudad Universitaria. La Librería, Madrid, 128-398. (in Spanish)

[13] Muñoz Hernández, J., González Casas, J.L. (2019). Traces and scars: The reconstruction of Madrid's Ciudad Universitaria after the Spanish Civil War. WIT Transactions on The Built Environment, 191: 211-222. http://dx.doi.org/10.2495/STR190181

[14] Rodríguez-López, C. (2002). The University of Madrid during the first Francoism (1939-1951): Rupture and continuity. Dykinson, Madrid. (in Spanish).

[15] Moya González, L. (2008). Madrid's Ciudad Universitaria: an early 20th century urban project considered today. In López Ríos, S., González Cárceles, J.A. (eds.) The Faculty of Philosophy and Letters of Madrid in the Second Republic. Architecture and University during the 30s. Ayuntamiento de Madrid: Madrid, 93-99.

\section{NOMENCLATURE}

AGUCM Archivo General de la Universidad Complutense de Madrid 